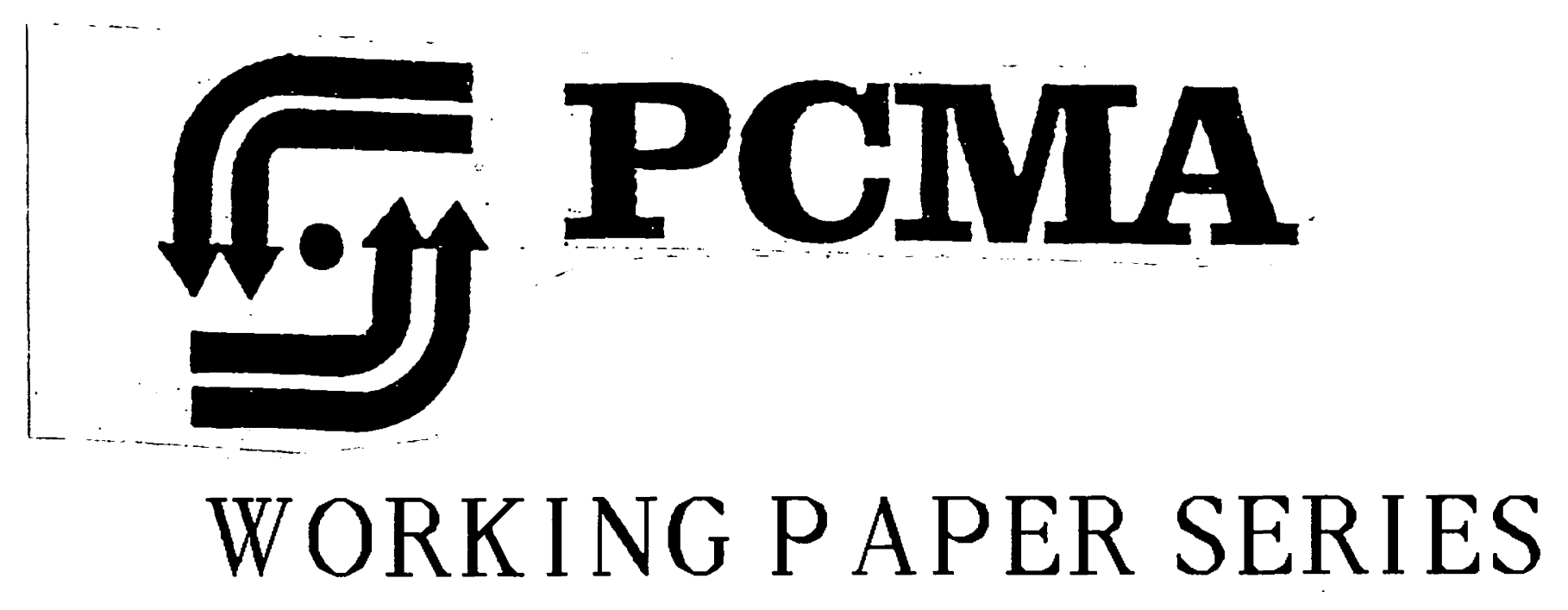

HEALTH EDUCATION AND COMMUNITY EMPOWERMENT:

CONCEPTUALIZING AND MEASURING PERCEPTIONS OF INDIVIDUAL, ORGANIZATIONAL AND COMMUNITY CONTROL

\author{
PCMA WORKING CRSO WORKING \\ $P A P E R * 38 \quad$ PAPER * 493 \\ March 1993
}

The Program on Conflict Management Alternatives at The University of Michigan 
HEALTH EDUCATION AND COMMUNITY EMPOWERMENT:

CONCEPTUALIZING AND MEASURING PERCEPTIONS OF INDIVIDUAL,

ORGANIZATIONAL AND COMMUNITY CONTROL

Barbara A. Israel, Dr. P.H.

Associate Professor

School of Public Health

University of Michigan

Barry Checkoway, Ph.D.

Professor

School of Social Work

University of Michigan

Amy Schulz, M.P.H.

Research Associate

Department of Sociology

University of Michigan

Marc Zimmerman, Ph.D. Assistant Professor

School of Public Health

University of Michigan

An earlier version of this paper was presented at the Annual Meeting of the American Public Health Association, New York, New York, October 2, 1990. We also thank Sue Andersen for her contribution in preparing this manuscript. We express our appreciation to Steven Rosenstone who was the Principal Investigator for the Detroit Area Study in which we developed and tested the measurement instrument presented here. 


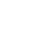




\begin{abstract}
The prevailing emphasis in health education is on understanding and changing life-style choices and individual health behaviors related to health status. While such approaches are appropriate for some health problems, they often ignore the association between increased morbidity and mortality and social, structural and physical factors in the environment, such as inadequate housing, poor sanitation, unemployment, exposure to toxic chemicals, occupational stress, minority status, powerlessness or alienation, and the lack of supportive interpersonal relationships. A conceptual model of the stress process incorporates the relationships among these environmental factors, powerlessness (or conversely empowerment), social support, and health status.

The concept of empowerment has been examined in diverse academic disciplines and professional fields. However, there is still a lack of clarity on the conceptualization of empowerment at different levels of practice, including its measurement, relationship to health, and application to health education. The purpose of this article is to address these issues as they relate to the concept of community empowerment. It provides a definition of community empowerment that includes individual, organizational, and community levels of analysis; describes how empowerment fits within a broader conceptual model of stress and its relationship to health status; and examines a series of scales that measure perceptions of individual, organizational, community and multiple levels of control. The article concludes with broad guidelines for and barriers to a community empowerment approach for health education practice.
\end{abstract}



HEALTH EDUCATION AND COMMUNITY EMPOWERMENT: CONCEPTUALIZING AND MEASURING PERCEPTIONS OF INDIVIDUAL, ORGANIZATIONAL AND COMMUNITY CONTROL

The fundamental conditions and resources for health are peace, shelter, education, food, income, a stable eco-system, sustainable resources, social justice and equity. Improvement in health requires a secure foundation in these basic prerequisites. (1)

The prevailing emphasis in health education interventions is on understanding and changing factors that affect life-style choices and individual health behaviors related to health status. While such approaches to changing individual behavior are appropriate for addressing some health problems, they often ignore the association between increased morbidity and mortality and social, structural and physical factors in the environment such as inadequate housing, poor sanitation, unemployment, exposure to toxic chemicals, occupational stress, minority status, poor education (2-10), powerlessness or lack of control or alienation $(3,11$ $16)$, and the lack of supportive interpersonal relationships $(2,17)$. A conceptual model of the stress process incorporates the relationships among these environmental factors, powerlessness (or conversely empowerment), social support, and mental and physical health status (2).

Many of these risk factors are beyond the ability of any one individual to control or change. Exposure to water contaminated by hazardous waste is neither caused nor eliminated by a single individual but reflects social processes and inequalities. Toxic production and waste facilities have been found to be disproportionately located in poor and minority communities whose residents lack access to and influence over decision makers (18). Also, access to nutritious and affordable food in low income communities is not determined by the individuals residing within them, but by processes of production and distribution which reflect regional, national, and international corporate and governmental interests. 
Health educators committed to improving health and well-being might want "to teach" individuals how to find alternative water or food supplies, but this approach has the danger of both blaming the victim (19) and doing little to eliminate the source of the problem itself. Health educators particularly committed to meeting the needs of economically, culturally or ethnically marginalized people need to work with them to obtain the basic prerequisites of health as defined by the Ottawa Charter for Health Promotion (presented above, 1). This requires that health educators not just develop programs aimed at individual behavior change, but also engage in collective action for social change (20-21). Application of the concept of empowerment within a framework of the stress process at the community level can provide health educators with useful guidelines for understanding the complex determinants of health, and can inform the design, conduct and evaluation of community-based health education programs.

The concept of empowerment has been examined at different levels of practice in diverse academic disciplines and professional fields $(3,7,8,11,16$, 2231). Within this literature, there have been numerous discussions of measurement issues and calls for the development of instruments to measure empowerment. However, there is still a lack of clarity on how empowerment is conceptualized at different levels of practice, its relationship to health, its measurement, and its application to health education practice. The purpose of this article is to address these issues as they relate to the concept of community empowerment. It provides a definition of community empowerment that includes individual, organizational, and community levels of analysis; describes how empowerment fits within a broader conceptual model of stress and its relationship to health status; and examines a series of scales that measure perceptions of individual, organizational, community and multiple levels of control. The article concludes with broad guidelines for and barriers to a community empowerment approach for health education practice. 


\section{WHAT IS COMMUNITY?}

In order to use the concept of empowerment and conceptual framework of the stress process to guide health education strategies at the community level, it is important to clarify what is meant by "community". While there are many definitions of community (e.g., 32-38), the one used here draws upon Sarason (33), Klein (32), and Steuart (34). A community is a locale or domain that is characterized by the following elements: 1) membership - a sense of identity and belonging; 2) common symbol systems - similar language, rituals and ceremonies; 3 ) shared values and norms; 4) mutual influence - community members have influence and are influenced by each another; 5) shared needs and commitment to meeting them; and 6) shared emotional connection - members share common history, experiences, and mutual support. Communality may be geographically bounded (e.g., a neighborhood), but is not necessarily (e.g., an ethnic group). Furthermore, a city or catchment area may be just an aggregate of non-connected people, may include numerous communities, or may have little sense of communality. Different neighborhoods within a city will vary in the extent to which they have a sense of community.

This definition of community is important for the present discussion because a community empowerment approach within the stress framework - with its emphasis on collective analysis, action and control - suggests that the health educator needs to identify and work within contexts which already show some sense of community. If this is not the case, then the initial task is to try to strengthen communality, or recognize that the individual, family, or social network may be more appropriate as the unit of practice.

\section{WHAT IS COMMUNITY EMPOWERMENT?}

The concept of empowerment has been examined in diverse disciplines and professional fields $(3,7-8,11,16,22-31)$ with widely varying definitions and 
assumptions. The purpose here is not to review this extensive literature (see for example, 8, 26-30), rather, the aim in this article is to highlight the major definitional and conceptual issues regarding community empowerment within the context of the stress model, and to discuss the relationship of these issues to health education practice and the measurement of empowerment.

Empowerment, in its most general sense, refers to the ability of people to gain understanding and control over personal, social, economic and political forces in order to take action to improve their life situations $(24,27,30)$. In contrast to reactive approaches which derive from a treatment or illness model, the concept of empowerment is positive and proactive. Empowerment is often defined for different levels of analysis and practice - e.g., individual, organizational, and community. Linkages among levels are a topic of considerable debate and will be discussed following definitions of each of the levels.

Individual or psychological empowerment refers to an individual's ability to make decisions and have control over his or her personal life. It is similar to other constructs such as self-efficacy (39) and self-esteem (40) in its emphasis on the development of a positive self-concept or personal competence. In addition, psychological empowerment incorporates the establishment of a critical or analytical understanding of the social and political context, and the cultivation of both individual and collective resources and skills for social action (41). Thus, empowerment at the individual level combines 1) personal efficacy and competence, 2) a sense of mastery and control, and 3) a process of participation to influence institutions and decisions $(26,42)$. Empowerment at the individual level is linked with the organizational and community levels through the development of personal control and competence to act, social support, and the development of interpersonal, social and political skills $(41,43)$. 
The literature on organizational empowerment draws heavily from democratic management theory (44). Empowering organizations are democratically managed, in which members share information and power, utilize cooperative decision-making processes, and are involved in the design, implementation, and control of efforts toward mutually defined goals. Consequently, they empower individuals as part of the organizational process. Empowering organizations recognize and incorporate cross-cutting linkages among members, such as interest groups, status groups, and formal sub-units. An empowered organization also has influence within the larger system of which it is a part $(26,45)$. Thus, empowerment at the organizational level incorporates both processes that enable individuals to increase their control within the organization, and the organization to influence policies and decisions in the larger community. This conception of organizations as both empowered and empowering helps provide the link between the organization level and the individual and community levels of empowerment (43).

An empowered community is one in which individuals and organizations apply their skills and resources in collective efforts to meet their respective needs. Through such participation, individuals and organizations within an empowered community provide enhanced support for each other, address conflicts within the community, and gain increased influence and control over the quality of life in their community. Similar to an empowered organization, an empowered community has the ability to influence decisions and changes in the larger social system. Hence, empowerment at the community level is connected with empowerment at the individual and organizational levels (43). This conceptualization is similar to the definition of neighborhood empowerment as composed of "capacity and equity" (46), where capacity is defined as the use of power to solve problems and equity is defined as getting a fair share of resources. 
Researchers and practitioners continue to debate the relationships among individual, organizational, and community levels of empowerment; whether the three levels can be addressed separately or simultaneously, and whether one level leads to another (45). Although professionals generally agree that all levels need to be targeted, much of the literature on empowerment focuses on the individual level. We argue that for empowerment to be a meaningful concept, distinct from others such as self-esteem and self-efficacy, the cultural, historical, social, economic and political context within which the individual exists must be recognized. It is possible to develop a program aimed at individual empowerment, but if this does not consider the context in which the individual is embedded - such as the organization or community - then there is less likelihood that actual increases in influence and control and concomitant improvement in health and quality of life will occur. Thus, while the three levels have important independent properties, they are not mutually exclusive.

This perspective highlights not just empowerment at multiple levels, but also the combination of empowerment across all three levels. Freire's (23) concept of conscientization provides a foundation for linking these three levels. Conscientization involves the development of a sense of identification with a group, of shared fate with that group, and of self and collective efficacy. The latter component involves both the belief that effective action is possible, and the capability (skills and resources) to develop effective strategies for action. Through a dialectical process of collective reflection and action (i.e., praxis), individuals, organizations, and the community as a whole develop the capacity to act effectively to create social change $(22,23,47)$.

While we do not wish to suggest that a single focus on the individual, organization, or community alone is not viable, we do argue that a model of community empowerment that links all three levels provides the most effective 
means to collectively provide the support and control necessary to develop needed skills, resources, and change. This multilevel concept of community empowerment suggests that change at one level will be associated with changes at other levels (43). In accordance with this model, as action at the organizational or community level results in enhanced collective problem-solving capabilities and increased influence and control over resources, those individuals involved in the process will experience greater control, and individual empowerment will be increased. We use the term "community empowerment" to refer to this multilevel concept to clearly differentiate from the frequent use of the term "empowerment" as an individual level construct.

\section{Critical Issues and Dimensions of Community Empowerment}

In addition to the definition of community empowerment, there are other issues that also have implications for community health education practice and research. These include the role and conceptualization of power; empowerment as a process and outcome; actual or perceived empowerment; and domain and time frame.

The role and conceptualization of power in relation to the concept of empowerment has been addressed extensively in the literature $(16,22-23,29,31,45$, 48). The responsible exercise of power is central to the concept of community empowerment. A community empowerment model transcends hierarchical, patriarchal, coercive, or violent conceptualizations of power (45), and challenges the assumption that power is a zero-sum commodity, that is, increasing the power of one community, organization or individual implies decreasing the power of another (29, 49). A community empowerment model emphasizes participation, caring, sharing, responsibility to others, and conceives of power as an expanding commodity (45).

Another central issue in the literature concerns whether empowerment is a process and/or an outcome. Used as a verb, "to empower" refers to a process through which people gain influence and control over their lives, and hence, become 
empowered. It is important here to distinguish between the primary dictionary definition of "empower" - to invest or give power or authority to others; and the secondary definition - to enable others, or to give others abilities in order that they may obtain power through their own efforts (29). It is critical for health educators trying to facilitate an empowering process, to adhere to this latter definition. That is, health educators cannot "give" power to people, but can enable others to strengthen skills and resources to gain power over their lives (30).

Used as a noun, empowerment refers to a state of being empowered as an outcome of the process. Focusing on empowerment as an outcome of a health education intervention provides one measure of the success of the process. It is one thing to know that people are engaged in a process of strengthening the skills and resources needed to have influence and control over their lives. It is another to know that the process results in the attainment of these goals and the ability to transfer lessons learned in one situation to other areas (45). We argue, as have others $(16,29,45)$, that empowerment is both a process and an outcome: this has important implications for intervention strategies and measurement. For example, different data collection methods are needed to assess the process of collective action within a community, and the resulting increase in power and control of the people involved.

This discussion leads to another issue regarding whether empowerment refers to perceived feelings of power and control, or to the actual reality of the reallocation of power and resources through structural change (29). While perception and subjective experience are critical, without actual changes in the objective reality the end stage of empowerment has not occurred. From a measurement perspective, this issue raises another concern regarding the limitations of using only self-report measures (an example to be presented below) to assess objective reality. 
The process of empowering communities is dynamic and ever-changing. A community and its constituent individuals and organizations can be empowered in some domains but not in others, and at some times but not at others (45). For example, a community may be successful in influencing the development of needed health services, but may not be as effective in keeping jobs in the community. Empowerment cannot necessarily be achieved in the short run, but takes commitment to a long-term process - that is, empowerment over the "long haul" $(50)$.

\section{WHY A COMMUNITY EMPOWERMENT APPROACH TO HEALTH EDUCATION?}

Epidemiological, sociological, and psychological evidence of the relationship between influence, control and health, provides a rationale for a community empowerment approach to health education. For example, studies show an association between powerlessness (or similarly, learned helplessness, alienation, exploitation) and mental and physical health status (3,11-16). Other research has linked poverty - economic powerlessness - with high rates of social dysfunction, increased morbidity and mortality, and decreased access to primary and preventive care (3). Additional research has shown an association between the experience of stress and the development of diverse physical, psychological and behavioral disorders $(2,4,51,52)$. The conceptual model of the stress process incorporates most of these factors, and is presented here as a useful framework for guiding health education community empowerment interventions.

Research evidence suggests that stress is related to physiological, psychological, and behavioral outcomes; and that psychosocial factors, including control, play an important role in modifying levels of stress, health, or the relationship between stress and health $(2,4,12-15,51-55)$. This model is most often explained in terms of how an individual experiences the stress process (2). There are 
also some examples of its use in the identification of stress and the design of interventions at the organizational level $(2,56,57)$. In accordance with the community empowerment approach to health education being suggested here, the framework will be described as a guide to understanding stress and health within a community context. Thus, similar to the multilevel dimensions of community empowerment, the stress model presented here recognizes the interrelatedness of the role of stressors on health and quality of life at the individual, organizational and community levels.

The conceptual model of the stress process (Figure 1) posits five major elements: 1) stressors, or psychosocial-environmental conditions conducive to stress (e.g., death of key community leaders, daily hassles with a government official, powerlessness, poverty status, malnutrition, natural disaster, exposure to toxic chemicals); 2) perceptions of stressors as stressful by the individual or community members collectively; 3 ) immediate or short-term responses to perceived stress (e.g., elevated blood pressure, tenseness, alcohol use, reduction of jobs and property values); 4) enduring or long-term health outcomes stemming from perceptions and short-term responses (e.g., cardiovascular disease, anxiety disorder, alcoholism, destroyed water quality, industrial and residential relocation); and 5) conditioning variables (characteristics of individuals and the situation) that influence the relationship among the first four elements (e.g., presence or absence of supportive relationships, community problem-solving abilities, community control, socioeconomic status) (2).

Figure 1 here

The psychosocial-environmental conditions conducive to stress include five categories of stressors. Each of these categories contains stressors that could be experienced throughout a community, rather than just a stressor of an isolated 
individual. Below are definitions of each of these categories with examples at the community level.

1. Major life events are the discrete events that disrupt normal activities and frequently require adaptive responses. While these usually apply to individuals more than communities, examples at the community level include a school or plant closing or death of a key community leader.

2. Daily hassles are minor events that occur in people's day-to-day lives that are perceived as frustrating or bothersome (58). For example, within a community exposed to contaminated water, members may experience ongoing disagreements with a government official or arguments with an industry representative.

3. Chronic stressors are the challenges, hardships and problems that people or communities experience over long periods of time (53). Chronic stressors that may occur at a community level include poverty, long-term unemployment, lack of influence and control over decisions that affect the community - powerlessness, high crime rates, harrassment by the police, and racism.

4. Cataclysmic events are sudden disasters that require major adaptive responses from all people who experience them (59). At the community level these include hurricanes, earthquakes or discovery of toxic waste dumps.

5. Ambient stressors are continuous and often unchanging conditions in the physical environment (59). Examples include long-term exposure to toxic chemicals, noise or air pollution.

As shown in Figure 1, conditioning variables which mediate between stressors and health outcomes fall into four groups: social, psychological, biophysical and genetic. These variables influence how an individual or community experiences the stress process. As defined earlier, the concept of community control or empowerment is one of the social conditioning variables. Thus, for example, a community that has a history of coming together and collectively influencing decisions that effect the community - that is, an empowered community, will be better able to deal with subsequent stressful situations than a community with little control or influence.

The concept of social support - while not the focus of this article - is another element of the stress model that has relevance to a community empowerment approach. Extensive research suggests that social support may directly enhance health regardless of stress level, as well as protect people from negative 
consequences of stressful situations (2). Therefore, in those communities where members provide one another with emotional support (empathy, love, caring), instrumental support (tangible aid, services), informational support (advice, suggestions, information), and appraisal support (feedback, affirmation, social comparison) (4), members would be expected to be at less risk of the negative effects of stress than in communities where such mutual support does not exist.

This conceptual framework of the stress process suggests several broad guidelines for a community empowerment approach. Such health education interventions should seek to:

- reduce chronic community stressors (e.g., poverty and powerlessness) and ambient stressors (e.g., exposure to toxic wastes) through programs involving community members experiencing these conditions;

- strengthen conditioning variables such as control and social support within the community;

- foster collective action aimed at organizational, community and social change to achieve lasting and significant change in health and quality of life;

- focus on examination of the effects of interventions on psychological, behavioral, physical, and ecological well-being, rather that solely a categorical disease focus; and

- obtain community members' active involvement in and control over program planning, implementation and evaluation as a health enhancing process itself.

\section{HOW CAN COMMUNITY EMPOWERMENT BE MEASURED?}

In order to evaluate health education community empowerment interventions, it is important to develop a method for assessing the extent to which community empowerment exists in a given community and for documenting its development over time. While there have been numerous discussions in the literature of measurement issues and calls for the development of instruments, the multilevel concept of community empowerment has rarely been operationalized and measured. In this section we describe our experience in the development and pilot testing of such measures and discuss the limitations of the indices. (For an excellent discussion of measurement issues in general, see Wallerstein, 16.) 
Methods. Our measurement draws on research through the Detroit Area Study (DAS), a large, random sample survey conducted yearly at the University of Michigan. The research objectives of the study change depending upon the key faculty members who direct the project for a given year. The development of the survey instrument, the drawing up of the sample, the collecting of data through faceto-face interviews, and the analysis of the data is carried out by graduate students as part of their training experience, working in conjunction with the faculty director and several full and part-time research staff members.

The 1989 DAS examined the social, economic, and political profile of the city of Detroit and two surrounding counties; community members' views of the most important problems facing their communities; and the nature and extent of public involvement in community problem-solving (60). Face-to-face interviews (approximately 1 hour in length) were conducted between April and August in 1989 with 916 randomly selected adults from forty-seven communities in the greater Detroit area. This involved a multi-stage area probability sample of housing units in the tri-county area, proportional to estimated sample size (466 residents), and an oversampling of residents in the city of Detroit (450 residents).

Measures. In the fall of 1988 , during the planning phase of the DAS, we were involved in a seminar series on empowerment, and were challenged by the lack of measurement instruments consistent with our multilevel conceptualization of community empowerment. Thus, we developed a set of twelve questions designed to assess individual perceptions of control or influence at the three levels of analysis - individual, organizational and community - for inclusion in the DAS survey. Our purpose was to develop indices measuring perceptions of control or influence at the three levels of analysis, to test the reliabilities of these indices, to develop a single scale including the three indices which could be used as a measure of the multilevel concept of empowerment, and to examine the correlates of perceptions of control 
by using other questions in the DAS survey (43). In accordance with our conceptualization of community empowerment across all three levels, the intent of the items at the organizational and community levels was to assess both perceptions of individual influence within an organizational and community context and the perceived influence of the organization and community within a broader sphere.

Our 12 questions were asked following others that inquired about the participants' involvement in numerous organizations (e.g., national organizations, neighborhood organizations, churches). The respondents were asked to identify all the organizations to which they belonged and to select the one that was the most important to them. The questions measuring perceived control at the organizational level were asked with regard to that organization. Participants who were not members of any organizations were not asked these questions. A four point response scale, ranging from $1=$ disagree strongly to $4=$ agree strongly, was used for all the items. The twelve items measuring perceptions of control are presented in Table 1.

Table 1 here

Results. Based on the results of a factor analysis, three subscales were created by summing the constituent items. Internal reliabilities of each of these indices and the overall community empowerment scale (all twelve items) were calculated using Cronbach's alpha as a measure of the average inter-item correlation. The three subscales correspond to perceived control at the individual level (the sum of items 6 and 8 in Table 1, alpha $=.66$ ), the organizational level (the sum of items 1 through 5, alpha=.61), and the community level (the sum of the values for items $7,9,10,11$, and 12 , alpha $=.63$ ). A multilevel scale that includes all twelve items was also created $($ alpha $=.71)$. Correlations among the three subscales 
were: .15 between individual and organizational; .22 between individual and community; and .39 between organizational and community.

Thus, the scale does appear to assess three levels of perceived control, and the organizational and community level indices tap both perceptions of individual influence within the two domains, and the perceived influence of the organization and the community in the larger environment. The instrument also provides a measure of community empowerment across all three levels as defined earlier. In an investigation examining the correlates of these measures of perceived control, we found that participation in organizations which attempt to influence public policy, taking an active or leadership role in a voluntary organization, and belief that taking action is an effective means to influence community decisions are important predictors of perceived control at the organizational and community levels (43).

Potential uses of the instrument. The perceived control indices could be used by a health educator engaged in a community empowerment intervention for both assessment and evaluation purposes. As part of the community diagnosis and needs assessment phases, the questions could be asked of community members individually and/or in a group setting and used to generate discussion among community members regarding their definition of empowerment and their assessment of the level of influence and control that individuals, organizations and the community have as a whole. The results of such a discussion could be used to guide the selection of specific action strategies aimed at enhancing community empowerment involving all three units of practice.

The measurement instrument could also be used in a survey to gather baseline data on perceptions of influence and control within a community or communities. Here again, the results of the aggregated survey data could be used to assess the extent to which perceived control exists as a resource or lack of control is present as a stressor that needs to be addressed. After the implementation of 
relevant interventions, a follow-up survey could be conducted to evaluate any changes in perceptions. Such a survey could also be used to investigate basic research questions longitudinally to further our understanding of the community empowerment concept, e.g., what are the major correlates of community empowerment, how do perceptions of control differ within subpopulations in a community, how do these change over time? There are, however, limits to the application of this instrument and these are examined below.

Limitations of the instrument. The scales described here provide a partial measure of empowerment, examining individual perceptions of control or influence at multiple levels. These perceptions were assessed by the use of a survey instrument with closed ended items which are not able to capture the richness and complexity of the community empowerment concept. For example, the development of conscientization (23) which has been identified as a key component of a multilevel empowerment perspective is not measured by these items, nor is there an assessment of the broader social-political-economic-cultural context that affects empowerment. The use of more in-depth, semi-structured interviews, focus groups, and community observations throughout a community empowerment intervention is needed to better assess empowerment as both a process and outcome. However, a relatively short survey instrument, as presented here, can be used with large numbers of participants to assess the level of and any changes in community empowerment. Thus, we suggest the simultaneous use of both quantitative and qualitative methods to measure community empowerment over time, for the purposes of problem identification, illumination of meaning, and triangulation of results (61).

A second limitation of this scale is that it measures individuals' perceptions of influence and control across levels. The scale neither measures actual control, nor obtains a collective assessment, at the organizational and community level, of 
perceived or actual control. Here again, observational and group assessment techniques would overcome these limitations. A third limitation of the scale is that the definition of community was not incorporated into the questionnaire; respondents answered the questions using individual and undetermined conceptions of community. The instrument would be most useful for intervention purposes if all respondents within a particular community were asked to answer the questions with the same community in mind.

Fourth, this instrument was developed and tested with respondents from a large urban area in the midwest involving primarily persons of either AfricanAmerican or European-American descent. The concepts of community, control and empowerment may differ across cultures and regions, and these variations need to be taken into consideration when adapting the scale to other areas. Finally, while this instrument was pretested with community members and revised based on their feedback, it was developed by the researchers based on their conceptualization of perceived control. An alternative approach, consistent with the definition of empowerment, would be to actively involve community members in the generation and testing of the questionnaire items.

Despite these limitations, as described earlier, the perceived control indices have potential use for health educators engaged in community empowerment interventions. It is important to acknowledge that many of these limitations apply to all closed-ended survey instruments, and that the concommitant strengths of using such a data collection approach are applicable to these indices as well (e.g., generalizability, reliability). The indices presented here are considered to be an initial formulation for assessing the multiple levels of perceived control. One of the next steps in this instrument development process is to use this measure in the context of a community empowerment intervention, along with other assessment methods, and to refine the scales as appropriate. The following section elaborates 
on the implications of a community empowerment perspective for health education practice.

\section{GUIDELINES FOR A COMMUNITY EMPOWERMENT PERSPECTIVE FOR HEALTH EDUCATION PRACTICE}

Health educators need to consider numerous factors in the design, implementation, and evaluation of community empowerment interventions. It is beyond the scope of this article to present a specific program example, rather a broad approach and several general guidelines for practice are suggested. First of all, in adherence with the tenets of community empowerment, with its emphasis on increased power and control across multiple units of practice, we suggest the use of a participatory action research approach. This approach involves practitioners, researchers and community members in a joint process to meet the specific needs of the community (intervention objectives) and to increase, for example, the understanding of empowerment and the effects of the interventions (research and evaluation objectives). Participatory action research (PAR) involves a cyclical problem-solving process of diagnosing, action planning, action taking, evaluating, and specifying learning (62). The key characteristics of the approach include: (adapted from 56):

1. It is participatory. The needs and problems addressed are generated by the community members themselves and not just by the theories and concerns of the health educators. The community members are involved in all aspects of the action and research $(62,63-65)$.

2. It is cooperative. Community members and health educators engage in a collaborative, joint process in which both contribute their expertise $(62,65-66)$.

3. It is a co-learning process. Health educators apply their theories and knowledge and also recognize and build on community members' "local theories" of the community (64).

4. It involves system development. Through the PAR process, a system (e.g., a community and its constituent organizations and individuals) develops the competencies to engage in the cyclical process of diagnosing and analyzing problems, and planning, implementing, and evaluating interventions aimed at meeting identified needs $(62,65)$. 
5. It is an empowering process. Through participation, community members, organizations, and the community as a whole gain increased influence and control, which is in turn associated with health and quality of life $(2,67)$.

6. It achieves a balance between research and action goals and objectives. Health educators and community members jointly determine and strive to maximize both increased knowledge and understanding of a given phenomenon, and jointly take actions to change the situation (68).

Thus, in choosing to use a participatory action research approach, a health educator can identify process and outcome goals and objectives that are consistent with the community empowerment concept. Using this approach, it is not possible for the health educator to define specific health problems or behaviors prior to joining with the community in this cooperative, co-learning process. However, from the perspective of the stress model presented earlier, the health educator can engage in a PAR project with the specified objectives of identifying and addressing sources of stress in the community, and the existence of conditioning variables (e.g., control, social support). The model of the stress process and the concept of community empowerment are most helpful in guiding health educators using a PAR approach in communities exposed to stressors that are beyond any one individual's ability to control (e.g., inadequate housing, violence, exposure to environmental hazards). In such situations, health education interventions are needed that involve collective action aimed at community and social change as well as individual change.

Using a PAR approach to reduce community stressors and to enhance community empowerment suggests several general guidelines for practice.

1. Program goals need to focus on reducing sources of stress as well as strengthening resources that may have a positive effect on stress and health, e.g., control, social support.

2. Program participants need to be actively involved and have infuence in all aspects of program planning, implementation and evaluation (e.g., interventions need to address the problems defined by the community itself).

3. Intervention outcomes need to include potential program effects on psychological, physical, behavioral and ecological/environmental well-being, not solely a categorical disease focus. 
4. Program goals and objectives need to specify, and measurement instruments need to assess, both the process of increasing influence and control (e.g., participation in community meetings), and the outcome of the process (i.e., actual influence over a decision that affects the community).

5. Program goals and objectives need to be designated, and quantitative and qualitative data collection instruments developed, that assess across individual, organizational and community levels of empowerment (e.g., the measures of perceived control presented here).

6. Community based activities need to establish operating norms that are consistent with the concept of empowerment, e.g., consensus decision-making, sharing of information and power, mutual respect and support.

7. Program activities need to be carried out in a way that ensures capacity building, skill development, and ownership of the process.

8. Community based activities need to balance efforts spent on action with critical reflection.

These principles of practice flow directly from the model of the stress process and the concept of community empowerment. Some are very similar to the basic tenets of health education practice, especially the relevant community organization models of community development, social action, and consciousness-raising $(8,23$ $24,34,69-72)$, and hence, these models provide additional specific suggestions for strategies and tactics appropriate for health education interventions aimed at community empowerment.

\section{WHAT ARE THE BARRIERS TO A COMMUNITY EMPOWERMENT PERSPECTIVE?}

While we advocate the application of the stress model and a community empowerment approach to health education, we also recognize that there are limitations and barriers to this approach. These may specifically relate to the community, to the health educator and his or her organization, and to external factors. The barriers include $(45,47)$ :

- situations where community members' past experiences and normative beliefs result in feelings that they do not have influence within the system (powerlessness, quiescence) and hence, they may feel that getting involved in an empowerment intervention would not be worthwhile; 
- differences in, for example, values, social class, race, ethnicity, that often exist between community members and health educators that may impede trust, communication, and collaborative work;

- difficulty in assessing/measuring community empowerment and being able to show that change has occurred;

- that this approach is not widely understood and valued by the health education profession;

- difficulty in facilitating an empowering process if one is working in an organization that is disempowering;

- the frequent perception that power is a finite commodity, rather than the concept of power as a resource that can be generated - which underlies the empowerment model;

- risks involved with challenging the status quo, for the individual, organizations and community as well as the health educator;

- difficulty for a community to transfer knowledge and skill gained in one arena (e.g., through the successful obtainment of needed health services) to other issues (e.g., development of an economic development program);

- that although individuals, organizations and local communities may gain power and resources within a limited area they may have no influence in the larger system;

- that a focus on the local community may not be effective in the long run in the context of today's global world.*

This discussion is not intended to dissuade the interested health educator, but rather to acknowledge that this is a complex process that cannot be accomplished over the short term. Nor is it a panacea which, once implemented, will resolve long-standing conflicts and inequalities. There are parties that will be threatened by any attempt to reduce major community level stressors and change the power structure. The health educator and the community need to consider carefully the potential resistances they may encounter. It is also important to recognize the change process as developmental, that involves time to enhance local

\footnotetext{
*As a colleague stated at a conference on empowerment: "In today's global world, what does the empowerment of one community mean? Can it be separated from all similarly affected communities? If we empower one group of workers in Appalachia to fight toxic waste, we may simply be moving the toxic chemicals to the Third World. Can empowerment occur at the individual or community level without being inclusive of the links globally? If we don't address this global structure, however, we can be turned against one another. So in the end we are disempowered as we struggle with the local issues." $(45$, p. 8$)$
} 
community empowerment, and time to link communities together for mutually beneficial collaboration in a more global community.

\section{CONCLUDING COMMENTS}

In this article we have provided a definition of community empowerment that includes individual, organizational and community levels of analysis, and have presented a rationale for a community empowerment approach for health education based on the conceptual model of the stress process. A series of scales that measure perceptions of individual, organizational, community, and multiple levels of control were examined, while recognizing the need for further measurement refinement and the use of multiple methods to assess community empowerment. We provided general practice guidelines for using a participatory action research approach to collaborate with community members as a means to both advance knowledge of this perspective and also strengthen the health and well-being of the people with whom we work.

We realize that this community empowerment perspective is not appropriate for all situations or for all health educators. Theory, however, is like a camera lens that helps us focus what we see and how we work within a given frame. Within this analogy, a telephoto lens brings fewer objects into focus and narrows our field of view. Similarly, a theory that considers only the relationship between individual behavior and physical illness allows only a narrow field of vision. On the other hand, when looking through a wide-angle lens many objects are in focus within a broad field of view; such is the case when using the stress model and the concept of community empowerment to guide our interventions. We suggest that health educators need to have multiple camera lenses in their repertoire, in order to view the diverse people and situations with which we work. These camera lenses then, and particularly the wide-angle lens that has been presented here, can be used to guide our thinking and action. In engaging in this process that at times can seem 
overwhelming, it is important to recall the practice principle of educator Myles Horton (50) that nothing good comes from desperation and despair, rather real change comes through hope. 


\section{REFERENCES}

1. World Health Organization, Health and Welfare of Canada. Ottawa Charter for Health Promotion. 1986.

2. Israel, B.A. and Schurman, S.J. Social support, control, and the stress process. In K. Glanz, F. Lewis and B. Rimer (Eds.) Health Behavior and Health Education: Theory, Research and Practice. San Francisco: Jossey-Bass, 1990

3. Braithwaite, R.L. and Lythcott, N. Community empowerment as a strategy for health promotion for black and other minority populations. JAMA, 261, 282283, 1989.

4. House, J.S. Work Stress and Social Support. Reading, MA: Addison-Wesley, 1981.

5. Freudenberg, N. and Golub, M. Health education, public policy and disease prevention: A case history of the New York City Coalition to End Lead Poisoning. Health Educ Q, 14, 387-401, 1987.

6. Montague, P. What we must do - A grass-roots offensive against toxics in the '90s. The Workbook, 14, 90-113, July-September 1989.

7. Rappaport, J. In praise of paradox: A social policy of empowerment over prevention. Am J Community Psychol, 9, 1-25, 1981.

8. Wallerstein, N.B. Empowerment education: Freire's theories applied to health. A case study of alcohol prevention for Indian and Hispanic youth. Dissertation, University of California, Berkeley, 1988.

9. USDHHS Secretary's Task Force. Report on black and minority health, Vol. 1. Executive Summary, August 1985.

10. Haan, M.N., Kaplan, G.A., and Camacho-Dickey, T. Poverty and health:

Prospective evidence from the Alameda County Study. Am J Epidemiol, 125, 989-998, 1987.

11. McKnight, J.L. Health and empowerment. Can J Public Health, 76, 37-38, 1985.

12. Albee, G. Powerless, politics and prevention. Paper presented at the meeting of the American Psychological Association, Washington, DC, August 1986.

13. Seligman, M. Helplessness. San Francisco: Freeman, 1975.

14. Ryan, W. Preventive services in the social context: Power, pathology, and prevention. In B.L. Bloom and D.P. Duck (Eds.), Preventive Services in Mental Health Programs, Boulder, CO: Western Interstate Commission for Higher Education, 49-58, 1967.

15. Seeman, M. and Seeman, T.E. Health behavior and personal autonomy: A longitudinal study of the sense of control in illness. J Health Soc Behav, 24, 144-160, 1983. 
16. Wallerstein, N. Powerlessness, empowerment, and health: Implications for health promotion programs. Am J Health Promotion, 6, 197-205, 1992.

17. Israel, B.A. and Rounds, K.A. Social networks and social support: A synthesis for health educators. Adv Health Educ Promotion, 2, 322-351, 1987.

18. United Church of Christ, Commission for Racial Justice. Toxic Wastes and Race in the United States: A National Report on the Racial and SocioEconomic Characteristics of Communities with Hazardous Waste Sites. New York, 1987.

19. Ryan, W. Blaming the Victim. New York: Vintage Press, 1971

20. Freudenberg, N. Shaping the future of health education: From behavior change to social change. Health Educ Q, $6,372-377,1978$.

21. Minkler, M. Health education, health promotion, and the open society: An historical perspective. Health Educ Q, 16, 17-30, 1989.

22. Freire, P. Pedagogy of the Oppressed. New York: The Seabury Press, 1970.

23. Freire, P. Education for Critical Consciousness. New York: The Seabury Press, 1973.

24. Kindervatter, S. Nonformal education towards empowering. Chapter VII in Nonformal Education as an Empowering Process. Amherst, MA: Center for International Education, 245-261, 1978

25. Rappaport, J. Terms of empowerment/exemplars of prevention: Toward a theory for community psychology. Am J Community Psychol, 15, 121-144, 1987.

26. Zimmerman, M.A. Psychological, organizational, and community empowerment: Directions for future research. To appear in J. Rappaport and E. Seidman (eds.), Handbook of Community Psychology, Plenum Press, 1990.

27. Gutierrez, L.M. Coping with stressful life events: An empowerment perspective. Working Paper, School of Social Work, University of Michigan, Ann Arbor, MI, 1988.

28. Kieffer, C.H. The emergence of empowerment: The development of participatory competence among individuals in citizen organizations. University of Michigan, Ann Arbor, MI, Dissertation, 1981.

29. Swift, C. and Levin, G. Empowerment: An emerging mental health technology. J Prim Prev, 8, 71-94, 1987.

30. Zimmerman, M.A. \& Rappaport, J. Citizen participation, perceived control, and psychological empowerment. Am J of Community Psychol, 16, 725-750, 1988. 
31. Labonté, R. Uniting for healthy communities. Paper presented at the opening session of the Annual Meeting of the American Public Health Association, Wasnington, D.C., November 9, 1992.

32. Klein, D. Community Dynamic and Mental Health. New York: John Wiley and Sons, 1968.

33. Sarason, S.B. The Psychological Sense of Community: Prospects For a Community Psychology. San Francisco: Jossey-Bass, 1984.

34. Steuart, G.W. Social and cultural perspectives: Community intervention and mental health. Paper presented at the Fourteenth Annual John W. Umstead Series of Distinguished Lectures, Raleigh, NC, 1978.

35. Warren, R.L. Types of purposive social change at the community level. In R.M. Kramer and H.Specht (Eds.), Readings in Community Organization Practice. Englewood Cliffs, NJ: Prentice Hall, 1975.

36. Warren, R.B. and Warren, D.I. What's in a neighborhood? The Neighborhood Organizer's Handbook. South Bend, IN: University of Notre Dame Press, 1977.

37. Wellman, B. and Leighton, B. Networks, neighborhoods and communities: Approaches to the study of the community question. Urban Affairs $Q, 14$, 363-390, 1979.

38. Heller, K. The return to community. Am J Community Psychol, 1-15, 1989.

39. Bandura, A. Self-efficacy mechanism in human agency. Am Psychol, 37, $122-$ $147,1982$.

40. Rosenberg, M. Society and the Adolescent Self-Image. Princeton, NJ: Princeton University Press, 1965.

41. Kieffer, C.H. Citizen empowerment: A developmental perspective. Prev Hum Serv, 3 , 9-36, 1984.

42. Zimmerman, M.A. Taking aim on empowerment research: On the distinction between psychological and individual conceptions. Am J Community Psychol, 18, 169-177, 1990.

43. Schulz, A.J., Israel, B.A., Zimmerman, M.A. and Checkoway, B.N. Empowerment as a multi-level construct: Perceived control at the individual, organizational and community levels. Under review, 1993.

44. Gibson, J.L., Ivancevich, J.M. and Donnelly, J.H. Organizations: Behavior, Structure, Processes. Dallas, TX: Business Publications, Inc., 1979.

45. Gerschick, T.J., Israel, B.A., and Checkoway, B. Means of empowerment in individuals, organizations, and communities: Report on a retrieval conference. Ann Arbor, MI: Program on Conflict Management Alternatives, University of Michigan, 1990. 
46. Biegèl, D. Help seeking and receiving in urban ethnic neighborhoods: Strategies for empowerment. In J. Rappaport, C. Swift and R. Hess (Eds.), Studies in Empowerment: Steps Toward Understanding and Action. New York: Haworth, 1984.

47. Schulz, A.J. and Israel, B.A. Empowerment and empowering processes: A theory developegnnt seminar series, Academic year 1988-89. Working Paper, Ann Arbor, MI: University of Michigan, July 1990.

48. Gruber, J. \& Trickett, E.J. Can we empower others? The paradox of empowerment in the governing of an alternative public school. Am J Community Psychol, 15, 353-371, 1987.

49. Bartunek, J. \& Keys, C. Power equalization in schools through organizational development. J Applied Behav Sci, 18, 171-183, 1982.

50. Horton, M. The Long Haul: An Autobiography. New York: Doubleday, 1990.

51. Cohen, S., Evans, G., Stokols, D. and Krantz, D. (Eds.) Behavior, Health and Environmental Stress. New York: Plenum, 1986.

52. Kasl, S.V. and Cooper, C.L. (Eds.) Stress and Health: Issues in Research Methodology. New York: John Wiley, 1987.

53. Pearlin, L.L. Role strains and personal stress. In H.B. Kaplan (Ed.), Psychosocial Stress: Trends in Theory and Research. New York: Academic Press, 1983.

54. Cottington, E.M. and House, J.S. Occupational stress and health: A multivariate relationship. In A.R. Baum and J.E. Hillsdale (Eds.), Handbook of Psychology and Health. Hillsdale, NJ: Erlbaum, 1987.

55. Holt, R. Occupational stress. In L. Goldberger and S. Breznitz (Eds.), Handbook of Stress: Theoretical and Clinical Aspects. New York: Free Press, 1982.

56. Israel, B.A. Schurman, S.J. and House, J.S. Action research on occupational stress: Involving workers as researchers. Int J Health Serv, 19, 135-155, 1989.

57. Katz, D. and Kahn, R. The Social Psychology of Organizations. New York: Wiley, 1978.

58. Delongis, A., Coyne, J.C., Dakof, G., Folkman, S. \& Lazarus, R.S. Relationship of daily hassles, uplifts and major life events to health status. Health Psychol, 1, 119-136, 1982.

59. Evans, G. and Cohen, S. Environmental stress. In D. Stokols and I. Altman (Eds.) Handbook of Environmental Psychology, Vol. 1. New York: Wiley, 1987.

60. Rosenstone, S. Separate and unequal: The racial divide: Strategies for reducing political and economic inequalities in the Detroit area. Detroit Area Study and Research Program on Race and American Politics, December 1989. 
61. Hugentobler, M.K., Israel, B.A. and Schurman, S.J. An action research approach to workplace health: Integrating methods. Health Educ Q, 19, 5576, 1992.

62. Susman, G.F. and Evered, R.D. An assessment of the scientific merits of action research. Admin Sci Q, 23, 582-603, 1978.

63. Brown, L.D. and Kaplan, R.E. Participative research in a factory. In P. Reason and J. Rowan (Eds.) Human Inquiry. Chichester: Wiley, 1981.

64. Elden, J.M. Sharing the research work: Participative research and its role demands. In P. Reason and J. Rowan (Eds.) Human Inquiry. Chichester: Wiley, 1986.

65. Kemmis, S. Action research. In D.S. Anderson and C. Blakers (Eds.) Youth, Transition and Social Research. Canberra: Australian National University Press, 1983.

66. Peters, M. and Robinson, V. The origins and status of action research. J Appl Behav Sci, 20, 113-124, 1984.

67. Elden, J.M. Political efficacy at work: The connection between more autonomous forms of workplace organizations and more participatory politics. Am Political Sci Rev, 75, 43-58, 1981.

68. Israel, B.A., Schurman, S.J. and Hugentobler, M.K. Conducting action research: Relationships between organization members and researchers. J Appl Behav

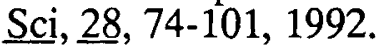

69. Minkler, M. Improving health through community organization. In K. Glanz, F.M. Lewis and B.K. Rimer (Eds.) Health Behavior and Health Education: Theory, Research and Practice. San Francisco: Jossey-Bass, 1990.

70. Tweeten, L. and Brinkman, G.L. Mobilizing community resources for development. In L. Tweeten and G.L. Brinkman, Micropolitan Development: Theory and Practice of Greater-Rural Economic Development. Ames, IA: The Iowa State University Press, 1976.

71. Minkler, M. and Cox, K. Creating critical consciousness in health: Applications of Freire's philosophy and methods to the health care setting. Int J Health Serv, $10,311-322,1980$.

72. Wallerstein, N. and Bernstein, E. Empowerment education: Freire's ideas adapted to health education. Health Educ Q, 15, 379-394, 1988. 


\section{TABLE 1}

Perceived Control Scale Items:

Multiple Levels of Empowerment Indices

For the first five items, the interviewer asked the participants to "please answer the following questions thinking about the organization that you identified as most important to you. Do you agree strongly, agree somewhat, disagree somewhat or disagree strongly?"

1. I can influence the decisions that this organization makes.

2. This organization has influence over decisions that affect my life.

3. This organization is effective in achieving its goals.

4. This organization can influence decisions that affect the community.

5. I am satisfied with the amount of influence I have over decisions that this organization makes.

The interviewer then commented that "I have been asking about your participation in specific organizations. I am also interested in how much influence you think you have in your life and in your community. I am going to read you a list of statements. For each one, please tell me how strongly you agree or disagree."

6. I have control over the decisions that affect my life.

7. My community has influence over decisions that affect my life.

8. I am satisfied with the amount of control I have over decisions that affect my life.

9. I can influence decisions that affect my community.

10. By working together, people in my community can influence decisions that affect the community.

11. People in my community work together to influence decisions on the state or national level.

12. I am satisfied with the amount of influence I have over decisions that affect my community.

\section{Indices}

Perceived control at the individual level includes items 6 and 8 above (alpha $=.66$ )

Perceived control at the organizational level includes items 1 through 5 above $($ alpha $=.61)$

Perceived control at the community level includes items 7, 9, 10, 11 and 12 above $($ alpha $=.63)$

Perceived control at multiple levels includes all 12 items above (alpha $=.71)$ 
FIGURE 1

Conceptual Framework of the Stress Process: Individual and Community Level $(4,57)$

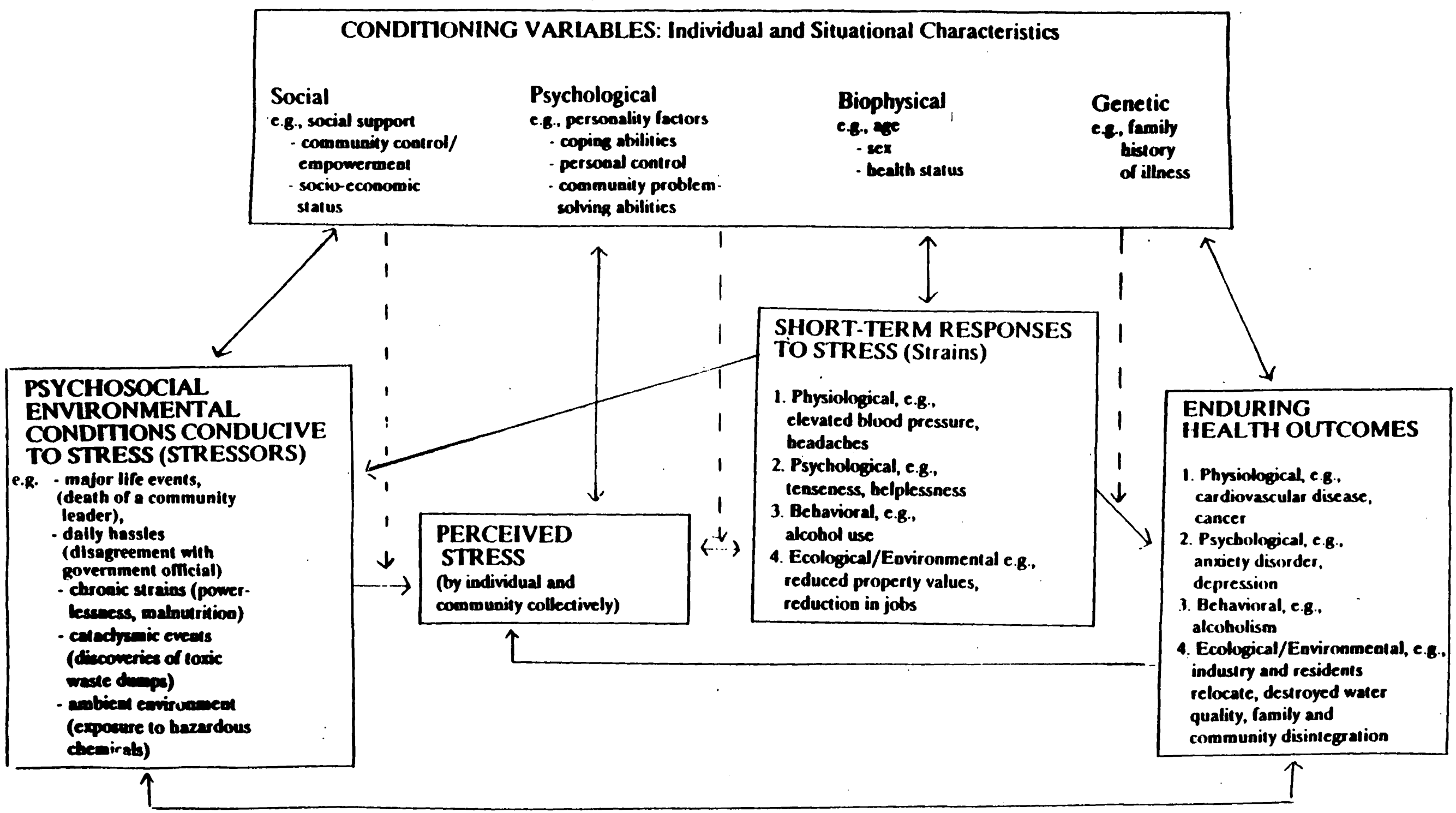

NOTE: Solid lines hetween boxes indicate presumed direct relationships among variables. Dotted lines indicate the bypotbesized buffering effects of the condinioning variables on the relationship between stressors and perceived stress, and perceived siress and short-term responses, and short-term responses and enduring healih outcomes. 